\title{
Qualidade dos Cardápios Escolares, Compra da Agricultura Familiar e Perfil de Municípios do Rio de Janeiro
}

\author{
Daniele da Silva Bastos Soares, ${ }^{1}$ Ânika Stephanie Aparecida Silva, ${ }^{2}$ \\ Patricia Camacho Dias, ${ }^{2}$ Patrícia Henriques, ${ }^{2}$ Daniele Mendonça Ferreira, ${ }^{2}$ \\ Roseane Moreira Sampaio Barbosa ${ }^{2}$
}

\section{RESUMO}

O objetivo deste estudo foi analisar a qualidade de cardápios escolares e verificar sua associação com a Agricultura Familiar (AF) e o perfil dos municípios do Rio de Janeiro (RJ). Cardápios escolares, obtidos nos sítios eletrônicos das prefeituras do RJ em setembro de 2017, foram analisados pelo método Análise Qualitativa de Preparações de Cardápios Escolares e as variáveis comparadas com Prado, Nicoletti e Faria (2013). Dados da compra da AF pelos municípios foram comparados com legislações do Programa Nacional de Alimentação Escolar. O número de habitantes/municípios foi utilizado para sua classificação quanto ao perfil demográfico. Os municípios foram classificados conforme perfil de organização espacial. Utilizou-se teste qui-quadrado para verificação da associação entre as variáveis marcadoras da alimentação saudável, a compra da AF e os perfis dos municípios. Todos os cardápios apresentaram frequência inadequada para verduras. Para frutas e legumes, cerca de $70 \%$ e $50 \%$ dos cardápios apresentaram frequência inadequada, respectivamente. Observou-se associação significativa entre o perfil de organização dos municípios e frequência de frutas. O cumprimento da legislação para a compra da AF na alimentação escolar não contribuiu para o aumento significativo de alimentos vegetais nos cardápios escolares do RJ.

Palavras-chave: alimentação escolar; planejamento de cardápio; política pública.

\section{QUALITY OF SCHOOL MENUS, PURCHASE OF FAMILY AGRICULTURE AND PROFILE} OF MUNICIPALITIES IN RIO DE JANEIRO

\section{ABSTRACT}

The objective of this study was to analyze the quality of school menus and verify their association with Family Agriculture (FA) and the profile of the municipalities of Rio de Janeiro (RJ). School menus, obtained at the websites of prefectures in RJ in September 2017, were analyzed by the method Qualitative Analysis of School Menu Preparations and the variables compared to Prado, Nicoletti e Faria (2013). Data on the purchase of PA by municipalities were compared with legislation of the National School Feeding Program. The number of inhabitants/municipalities was used for their classification as to the demographic profile. The municipalities were classified according to spatial organization profile. A chi-square test was used to verify the association between variables markers of healthy eating, the purchase of FA and the profiles of municipalities. All menus presented inadequate frequency for vegetables. For fruits and vegetables, about $70 \%$ and $50 \%$ of the menus presented inadequate frequency, respectively. It was observed a significant association between the organization profile of the municipalities and frequency of fruits. Compliance with the legislation for the purchase of FA in school meals did not contribute to the significant increase of vegetable foods in the school menus of RJ.

Keywords: school feeding; menu planning; public policy.

RECEBIDO EM: 18/11/2019

MODIFICAÇÕES SOLICITADAS EM: 23/10/2020

ACEITO EM: 29/1/2021

\footnotetext{
${ }^{1}$ Autora correspondente. Universidade Federal Fluminense, Faculdade de Nutrição. Rua Mário Santos Braga, 30 - Centro. Niterói/RJ, Brasil. CEP 24020-140. http://lattes.cnpq.br/1163585343443325. https://orcid.org/0000-0001-5196-9055. danielebastos@id.uff.br

2 Universidade Federal Fluminense. Niterói/RJ, Brasil.
} 


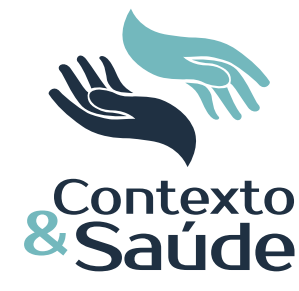

\section{INTRODUÇÃO}

A oferta de refeições nas escolas compõe a principal estratégia do Programa Nacional de Alimentação Escolar (PNAE) para a garantia do direito humano à alimentação adequada (DHAA) e saudável a todos os alunos matriculados na educação básica das redes públicas federal, estadual, distrital e municipal, incluindo alunos de entidades filantrópicas e conveniadas (BRASIL, 2009b). O atual desenho do PNAE pretende contribuir para o crescimento e o desenvolvimento, a aprendizagem, o rendimento escolar e a formação de práticas alimentares saudáveis dos alunos por meio da oferta de refeições que supram parte de suas necessidades nutricionais durante o período letivo, e da efetivação de ações de educação alimentar e nutricional (EAN) (BRASIL, 2009b).

Ao longo de sua história, o PNAE passou por diversas alterações nos instrumentos legais que contribuíram para a melhoria na qualidade dos cardápios escolares. Nesse sentido, um dos marcos mais significativos foi instituído pela Lei no 11.947 de 2009 (BRASIL, 2009a), que representa uma oportunidade de conexão entre a produção e o consumo de alimentos por meio da institucionalização da obrigatoriedade da compra de alimentos da agricultura familiar (AF) local. Esse mecanismo de compra pública propõe-se a estimular o desenvolvimento local sustentável com base na utilização de, no mínimo, 30\% do recurso transferido pelo Fundo Nacional de Desenvolvimento da Educação (FNDE) para Estados e municípios por meio da aquisição de gêneros alimentícios diversificados da AF e com respeito aos hábitos alimentares regionais (BRASIL, 2009b; FERIGOLLO et al., 2017).

Mais ainda, de acordo com Cruz et al. (2013), a inclusão de alimentos oriundos da AF representa um mecanismo de melhoria da qualidade alimentar e nutricional do cardápio escolar, em especial no que se refere ao aumento da oferta de alimentos de origem vegetal ao público escolar.

Cabe destacar que a qualidade dos cardápios escolares pode ser analisada sob distintos métodos, tendo em vista a existência de diferentes parâmetros e aspectos de mensuração da mesma, descritos na literatura, que perpassam por métodos específicos, legislações do PNAE e pela classificação dos alimentos conforme o grau de processamento (TEO; MONTEIRO, 2012; BRASIL, 2014; SOARES et al., 2015). Desse modo, embora os métodos para análise de qualidade dos cardápios escolares possam estar focados em distintos aspectos da alimentação saudável, de um modo geral todos sugerem que o predomínio de alimentos in natura e/ou básicos devem compor prioritariamente o perfil alimentar escolar. A relação entre a aquisição de gêneros da AF e os diferentes aspectos que qualificam os cardápios escolares, no entanto, ainda carece de investigação.

Nesse sentido, o método Avaliação Qualitativa das Preparações de Cardápios (AQPC) destaca-se como uma ferramenta para análise de cardápios, promovendo uma visão ampla quanto à sua qualidade nutricional e sensorial (BOITO et al., 2019). O AQPC Escola (AQPCE), por sua vez, é um método derivado do AQPC destinado à análise de cardápios escolares a fim de auxiliar o responsável técnico nutricionista no diagnóstico e avaliação dos mesmos com base na presença de alimentos controlados e recomendados, considerando, principalmente, as reco- 
mendações propostas pelo PNAE para uma alimentação adequada, saudável e sustentável (VEIROS; MARTINELLI, 2012; BOAVENTURA et al., 2013; SILVA et al., 2016).

Desse modo, o caráter recente das legislações que relacionam o PNAE e a AF e a escassez de estudos que analisam a relação entre a qualidade de cardápios escolares planejados e a compra de gêneros da AF em municípios com distintas características, justificam a realização do presente estudo.

\section{OBJETIVO}

O objetivo deste trabalho foi analisar a qualidade de cardápios escolares planejados bem como verificar a associação de marcadores da alimentação saudável nos cardápios escolares com a compra da AF e o perfil demográfico e de organização espacial dos municípios do RJ.

\section{MATERIAIS E MÉTODOS}

\section{Tipo de estudo}

Tratou-se de um estudo com delineamento transversal, do tipo descritivo e quantitativo, que avaliou a qualidade alimentar e nutricional dos cardápios dos almoços planejados para escolares, a compra da AF e o perfil dos municípios do Estado do RJ.

Foram considerados unidade amostral os cardápios dos almoços planejados, com a descrição do público-alvo para escolares de 6 a 10 anos dos 92 municípios do Estado do RJ durante o mês de setembro de 2017. Os cardápios foram obtidos a partir do acesso a sítios eletrônicos das Prefeituras do RJ.

A análise dos cardápios planejados de uma refeição (almoço) foi conduzida levando-se em conta a Resolução $n^{\circ} 26$ de 2013 do FNDE (BRASIL, 2013a), que prevê valores de referência nutricionais a serem atendidos pelo PNAE a partir de uma ou mais refeições planejadas para o público escolar.

Os cardápios planejados para escolas pertencentes à Rede Estadual de ensino do RJ não foram considerados objetos de análise neste estudo, tendo em vista que estas escolas atendem a alunos do Ensino médio e, de um modo geral, pertencente a outra faixa etária.

\section{Avaliação Qualitativa das Preparações de Cardápios Escolares (AQPCE) dos municípios do Estado do RJ}

Os cardápios escolares foram analisados por meio do método AQPCE, com base em 16 variáveis distribuídas em dois grupos - alimentos recomendados e alimentos controlados -, de acordo com Veiros e Martinelli (2012).

Após a determinação da presença de cada variável durante os 20 dias de cardápios dos almoços, foram obtidos os percentuais de ocorrência mensal por variável em cada cardápio do almoço do município. Os percentuais obtidos, de cada variável por município, foram classificados com os parâmetros estabelecidos por Prado, Nicoletti e Faria (2013) (Quadro 1) e as classificações ótima e boa 
foram consideradas adequadas, enquanto as regular, ruim e péssima, como inadequadas.

Os resultados obtidos foram expressos em valores absolutos ( $n$ ) e relativos (\%) das classificações ótima, boa, regular, ruim e péssima, por variável, em relação ao número total de cardápios planejados dos almoços para escolares (6-10 anos) dos municípios do RJ analisados neste estudo.

Quadro 1 - Pontos de corte para classificação dos resultados percentuais das variáveis relacionadas aos alimentos recomendados e aos controlados dos cardápios dos almoços planejados para escolares (6-10 anos) analisados pelo método AQPCE (VEIROS; MARTINELLI, 2012)

\begin{tabular}{|c|c|c|}
\hline Classificação & $\begin{array}{c}\text { Variáveis relacionadas aos ali- } \\
\text { mentos recomendados }\end{array}$ & $\begin{array}{c}\text { Variáveis relacionadas aos } \\
\text { alimentos controlados }\end{array}$ \\
\hline Ótimo & $\geq 90 \%$ & $\leq 10 \%$ \\
\hline Bom & 75 a $89 \%$ & 11 a $25 \%$ \\
\hline Regular & 50 a $74 \%$ & 26 a $50 \%$ \\
\hline Ruim & 25 a $49 \%$ & 51 a $75 \%$ \\
\hline Péssimo & $<25 \%$ & $>75 \%$ \\
\hline
\end{tabular}

Fonte: PRADO; NICOLETTI; FARIA (2013).

\section{Análise da compra da AF, do perfil demográfico e do perfil de organização espacial nos municípios do Estado do RJ}

Dados secundários relacionados à compra da AF dos municípios do RJ para o ano de 2016, e cujos cardápios escolares estavam disponíveis nos sítios eletrônicos das Prefeituras do RJ e puderam ser analisados conforme metodologia apresentada anteriormente, foram obtidos por meio do acesso ao sítio eletrônico do FNDE (BRASIL, 2016b) e comparados com as legislações vigentes do PNAE (BRASIL, 2009b; BRASIL, 2013a).

Informações secundárias sobre o número de habitantes dos municípios do RJ de 2017, cujos cardápios escolares foram analisados neste trabalho, também foram obtidas por intermédio do sítio eletrônico do Instituto Brasileiro de Geografia e Estatística (IBGE) (BRASIL, 2017) e utilizadas para classificação dos municípios quanto ao perfil demográfico (pequeno, médio ou grande) (BRASIL, 2011). Os municípios também foram classificados de acordo com sua organização espacial (rural ou urbano), de acordo com Brasil (2017).

\section{Análise Estatística}

A associação entre as variáveis marcadoras da alimentação saudável, isto é, frutas, vegetais não amiláceos (legumes), vegetais folhosos (verduras) e raízes/ tubérculos, nos cardápios escolares, a compra da AF, $\square$ ou $<$ dos $30 \%$ do recurso transferido do FNDE, e os perfis demográfico - pequeno, médio ou grande - e de organização espacial - rural ou urbano - nos municípios do RJ, foi verificada por meio do teste qui-quadrado, considerando significância estatística quando $\mathrm{p}<0,05$.

Os alimentos de origem vegetal foram eleitos neste estudo como os marcadores da alimentação saudável em virtude das diretrizes do PNAE (BRASIL, 
2009b), que preconizam o incremento destes alimentos nas refeições para a promoção da alimentação saudável e adequada no ambiente escolar.

\section{RESULTADOS}

A partir do acesso aos 92 sítios eletrônicos das Prefeituras do RJ, foram identificados 23 cardápios escolares (25\%) disponíveis.

$\mathrm{Na}$ Tabela 1 estão dispostos os resultados referentes às classificações das variáveis (PRADO; NICOLETTI; FARIA, 2013) dos cardápios dos almoços para escolares ( 6 a 10 anos) de 23 municípios do RJ, durante os vinte dias letivos do mês de setembro de 2017, analisados pelo método AQPCE (VEIROS; MARTINELLI, 2012)

Tabela 1 - Resultados absolutos (n) e relativos (\%) das classificações das variáveis nos cardápios dos almoços para escolares (6 a 10 anos) analisados pelo método AQPCE de 23 municípios do RJ (setembro de 2017)

\begin{tabular}{|c|c|c|c|c|c|c|c|c|c|c|}
\hline \multirow{3}{*}{$\begin{array}{c}\text { Variáveis segundo o } \\
\text { método AQPCE (VEI- } \\
\text { ROS; MARTINELLI, } \\
\text { 2012) }\end{array}$} & \multicolumn{10}{|c|}{$\begin{array}{l}\text { Classificação dos percentuais das variáveis nos cardápios escolares } \\
\text { (PRADO; NICOLETTI; FARIA, 2013) }\end{array}$} \\
\hline & \multicolumn{2}{|c|}{ Ótimo } & \multicolumn{2}{|c|}{ Bom } & \multicolumn{2}{|c|}{ Regular } & \multicolumn{2}{|c|}{ Ruim } & \multicolumn{2}{|c|}{ Péssimo } \\
\hline & $\mathrm{n}$ & $\%$ & $\mathrm{n}$ & $\%$ & $\mathrm{n}$ & $\%$ & $\mathrm{n}$ & $\%$ & $\mathrm{n}$ & $\%$ \\
\hline $\begin{array}{c}\text { Alimentos recomenda- } \\
\text { dos: } \\
\text { Frutas in natura }\end{array}$ & 7 & 30,4 & 0 & 0 & 9 & 39,1 & 3 & 13 & 4 & 17,4 \\
\hline $\begin{array}{l}\text { Saladas de vegetais } \\
\text { folhosos }\end{array}$ & 0 & 0 & 0 & 0 & 2 & 8,7 & 4 & 17,4 & 17 & 73,9 \\
\hline Vegetais não amiláceos & 2 & 8,7 & 9 & 39,1 & 11 & 47,8 & 0 & 0 & 1 & 4,4 \\
\hline $\begin{array}{l}\text { Cereais, pães, massas e } \\
\text { vegetais amiláceos }\end{array}$ & 22 & 95,7 & 1 & 4,4 & 0 & 0 & 0 & 0 & 0 & 0 \\
\hline Alimentos integrais & 0 & 0 & 0 & 0 & 0 & 0 & 0 & 0 & 23 & 100 \\
\hline Carnes e ovos & 21 & 91,3 & 2 & 8,7 & 0 & 0 & 0 & 0 & 0 & 0 \\
\hline Leguminosas & 13 & 56,5 & 5 & 21,7 & 5 & 21,7 & 0 & 0 & 0 & 0 \\
\hline \multicolumn{11}{|l|}{ Alimentos controlados: } \\
\hline $\begin{array}{l}\text { Preparações alimentares } \\
\text { e produtos com açúcar }\end{array}$ & 13 & 56,5 & 2 & 8,7 & 5 & 21,7 & 1 & 4,4 & 2 & 8,7 \\
\hline $\begin{array}{l}\text { Embutidos e produtos } \\
\text { cárneos industrializados }\end{array}$ & 22 & 95,6 & 1 & 4,4 & 0 & 0 & 0 & 0 & 0 & 0 \\
\hline $\begin{array}{l}\text { Alimentos industriali- } \\
\quad \text { zados }\end{array}$ & 14 & 60,9 & 7 & 30,4 & 2 & 8,7 & 0 & 0 & 0 & 0 \\
\hline Enlatados e conservas & 17 & 73,9 & 5 & 21,7 & 1 & 4,4 & 0 & 0 & 0 & 0 \\
\hline $\begin{array}{l}\text { Alimentos concentrados } \\
\text { em pó ou desidratados }\end{array}$ & 23 & 100 & 0 & 0 & 0 & 0 & 0 & 0 & 0 & 0 \\
\hline $\begin{array}{l}\text { Alimentos flatulentos e } \\
\text { de difícil digestão }\end{array}$ & 1 & 4,4 & 5 & 21,7 & 9 & 39,1 & 7 & 30,4 & 1 & 4,4 \\
\hline $\begin{array}{l}\text { Bebidas com baixo teor } \\
\text { nutricional }\end{array}$ & 23 & 100 & 0 & 0 & 0 & 0 & 0 & 0 & 0 & 0 \\
\hline $\begin{array}{l}\text { Preparações com cores } \\
\text { similares na refeição }\end{array}$ & 4 & 17,4 & 8 & 34,8 & 11 & 47,8 & 0 & 0 & 0 & 0 \\
\hline $\begin{array}{l}\text { Frituras, carnes e mo- } \\
\text { Ihos gordurosos }\end{array}$ & 12 & 52,2 & 8 & 34,8 & 3 & 13 & 0 & 0 & 0 & 0 \\
\hline
\end{tabular}

Fonte: Dados da pesquisa. 


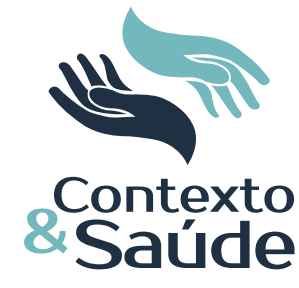

Quanto à presença de saladas de vegetais folhosos e alimentos integrais, todos os cardápios escolares apresentaram frequência mensal inadequada. Para a variável frutas in natura, a maior parte dos cardápios (cerca de 70\%) apresentou frequência mensal inadequada. Com relação aos cereais, pães, massas, vegetais amiláceos e carnes/ovos, todos os cardápios apresentaram ocorrência mensal adequada. Para as leguminosas, cerca de $22 \%$ dos cardápios mostraram frequência mensal inadequada, e, para os vegetais não amiláceos, metade dos cardápios apresentou ocorrência mensal inadequada (Tabela 1).

Para as classificações "ótimo" e "bom" nas variáveis relacionadas aos alimentos recomendados, os principais alimentos que contribuíram para estes resultados foram: arroz branco, feijão preto, carnes, guarnições à base de legumes cozidos e frutas como sobremesas.

Com respeito ao embutidos e produtos cárneos industrializados, alimentos concentrados, desidratados ou em pó e bebidas com baixo valor nutricional, todos os cardápios apresentaram frequência mensal adequada e, para os alimentos industrializados, enlatados/conservas e presença de frituras, carnes e molhos gordurosos nos cardápios, a maior parte de todos os cardápios escolares demonstrou ocorrência mensal adequada (91,3\%, 95,6\% e 87\%, respectivamente). Para as preparações e produtos com açúcar, cerca de $35 \%$ dos cardápios demonstraram frequência inadequada. Por outro lado, a maior parte dos cardápios apresentou frequência inadequada (74\%) para os alimentos flatulentos e, quanto à presença de preparações com cores similares, cerca de metade dos cardápios trouxe frequência inadequada. Em outras palavras, a maioria das variáveis relacionadas aos alimentos controlados apresentou resultados classificados como "ótimo" ou "bom", excetuando-se as preparações alimentares e produtos com açúcar, em razão da presença de refrescos adoçados, alimentos flatulentos e de difícil digestão e as preparações com cores similares na refeição (Tabela 1).

De um modo geral, os cardápios escolares dos almoços com classificações adequadas para a frequência mensal das variáveis relativas aos alimentos recomendados e aos controlados, apresentaram as seguintes preparações alimentares com variedade de cores: arroz, feijão, carne (bovina, frango ou peixe) ensopada, grelhada, cozida ou assada, guarnição à base de vegetal não amiláceo (legume) e/ou amiláceo (raiz ou tubérculo cozido) cozida, ensopada ou na forma de purê, e uma fruta como sobremesa.

A Tabela 2 apresenta os resultados da distribuição das frequências relacionadas à compra da AF e aos perfis demográfico e de organização espacial dos 23 municípios do RJ, cujos cardápios escolares puderam ser acessados e analisados no presente estudo.

Editora Unijuí - Revista Contexto \& Saúde - ISSN 2176-7114 - v. 21, n. 43, jul./set. 2021 
Tabela 2 - Frequências absolutas ( $\mathrm{n}$ ) e relativas (\%) relacionadas à compra da AF e aos perfis demográfico e de organização espacial de 23 municípios do RJ, cujos cardápios escolares foram analisados pelo método AQPCE (VEIROS; MARTINELLI, 2012) e os resultados dos percentuais das variáveis foram classificados segundo Prado; Nicoletti; Faria (2013)

\begin{tabular}{cccc}
\hline Variáveis & & n & \% \\
\hline \multirow{2}{*}{ Compra da AF } & 回 30\% & 18 & 78,3 \\
& ] $30 \%$ & 5 & 21,7 \\
\multirow{3}{*}{ Perfil demográfico } & Pequeno & 2 & 8,7 \\
& Médio & 17 & 73,9 \\
\multirow{3}{*}{ Perfil de organização espacial } & Grande & 4 & 17,4 \\
& Rural & 3 & 13,0 \\
& Urbano & 20 & 87,0 \\
\hline
\end{tabular}

Fonte: Dados da pesquisa.

Quanto à compra de alimentos para o cardápio escolar da AF, a maioria dos municípios, cujos cardápios foram analisados neste estudo, não atingiu os 30\% mínimos exigidos pelas legislações do PNAE (78,3\%), e foi classificada como de médio porte e urbano (73,9\% e 87,0\%, respectivamente) (Tabela 2 ).

A Tabela 3 apresenta os resultados do estudo de associação entre a frequência mensal de frutas, vegetais não amiláceos, vegetais folhosos e raízes/ tubérculos nos cardápios escolares, o percentual de compra da AF e os perfis demográfico e de organização espacial nos 23 municípios do RJ.

Tabela 3 - Associação entre as variáveis marcadoras da alimentação saudável dos cardápios escolares, a compra da AF e os perfis demográfico e de organização espacial nos 23 municípios do RJ

\begin{tabular}{|c|c|c|c|c|c|c|c|c|c|c|}
\hline & \multicolumn{3}{|c|}{$\begin{array}{l}\text { Compra da AF do } \\
\text { município }\end{array}$} & \multicolumn{2}{|c|}{$\begin{array}{l}\text { Perfil demográfico } \\
\text { do município }\end{array}$} & \multirow{2}{*}{\multicolumn{2}{|c|}{ Valor $p$}} & \multicolumn{2}{|c|}{$\begin{array}{l}\text { Perfil de organi- } \\
\text { zação espacial do } \\
\text { município }\end{array}$} & \multirow[t]{2}{*}{ alor $p$} \\
\hline & $<30 \%$ & $\geq 30 \%$ & & Pequeno & Médio & & & Rural & Urbano & \\
\hline \multicolumn{11}{|c|}{$\begin{array}{l}\text { Frequência men- } \\
\text { sal de frutas }\end{array}$} \\
\hline $\begin{array}{l}\text { Ótimo/ } \\
\text { Bom }\end{array}$ & $6(33,3 \%)$ & $1(20,0 \%)$ & & $\begin{array}{c}2 \\
(100,0 \%)\end{array}$ & $3(17,6 \%)$ & $\begin{array}{c}2 \\
(50,0 \%)\end{array}$ & & $\begin{array}{c}3 \\
(100,0 \%)\end{array}$ & $\begin{array}{c}4 \\
(20,0 \%)\end{array}$ & \\
\hline Regular & $7(38,9 \%)$ & $2(40,0 \%)$ & 0,810 & $\begin{array}{c}0 \\
(0,0 \%)\end{array}$ & $7(41,2 \%)$ & $\begin{array}{c}2 \\
(50,0 \%)\end{array}$ & 0,092 & $\begin{array}{c}0 \\
(0,0 \%)\end{array}$ & $\begin{array}{c}9 \\
(45,0 \%)\end{array}$ & $0,019 *$ \\
\hline $\begin{array}{l}\text { Ruim/ } \\
\text { Péssimo }\end{array}$ & $5(27,8 \%)$ & $2(40,0 \%)$ & & $\begin{array}{c}0 \\
(0,0 \%)\end{array}$ & $7(41,2 \%)$ & $\begin{array}{c}0 \\
(0,0 \%)\end{array}$ & & $0(00,0 \%)$ & $\begin{array}{c}7 \\
(35,0 \%)\end{array}$ & \\
\hline \multicolumn{11}{|c|}{$\begin{array}{l}\text { Frequência men- } \\
\text { sal de vegetais } \\
\text { não amiláceos }\end{array}$} \\
\hline $\begin{array}{l}\text { Ótimo/ } \\
\text { Bom }\end{array}$ & $9(50,0 \%)$ & $2(40,0 \%)$ & & $\begin{array}{c}0 \\
(0,0 \%)\end{array}$ & $\begin{array}{c}10 \\
(58,8 \%)\end{array}$ & $\begin{array}{c}1 \\
(25,0 \%)\end{array}$ & & $\begin{array}{c}1 \\
(33,3 \%)\end{array}$ & $\begin{array}{c}10 \\
(50,0 \%)\end{array}$ & \\
\hline Regular & $8(44,4 \%)$ & $3(60,0 \%)$ & 0,757 & $\begin{array}{c}2 \\
(100,0 \%)\end{array}$ & $6(35,3 \%)$ & $\begin{array}{c}3 \\
(75,0 \%)\end{array}$ & 0,344 & $2(66,7 \%)$ & $\begin{array}{c}9 \\
(45,0 \%)\end{array}$ & 0,757 \\
\hline $\begin{array}{l}\text { Ruim/ } \\
\text { Péssimo }\end{array}$ & $\begin{array}{c}1 \\
(5,6 \%)\end{array}$ & $\begin{array}{c}0 \\
(0,0 \%)\end{array}$ & & $\begin{array}{c}0 \\
(0,0 \%)\end{array}$ & $\begin{array}{c}1 \\
(5,9 \%)\end{array}$ & $\begin{array}{c}0 \\
(0,0 \%)\end{array}$ & & $\begin{array}{c}0 \\
(0,0 \%)\end{array}$ & $\begin{array}{c}1 \\
(5,0 \%)\end{array}$ & \\
\hline
\end{tabular}

Frequência men-

sal de vegetais

folhosos 


\begin{tabular}{|c|c|c|c|c|c|c|c|c|c|c|}
\hline $\begin{array}{l}\text { Ótimo/ } \\
\text { Bom }\end{array}$ & $\begin{array}{c}0 \\
(0,0 \%)\end{array}$ & $\begin{array}{c}0 \\
(0,0 \%)\end{array}$ & & $\begin{array}{c}0 \\
(0,0 \%)\end{array}$ & $\begin{array}{c}0 \\
(0,0 \%)\end{array}$ & $\begin{array}{c}0 \\
(0,0 \%)\end{array}$ & & $\begin{array}{c}0 \\
(0,0 \%)\end{array}$ & $\begin{array}{c}0 \\
(0,0 \%)\end{array}$ & \multirow{3}{*}{0,870} \\
\hline Regular & $\begin{array}{c}1 \\
(5,6 \%)\end{array}$ & $\begin{array}{c}0 \\
(0,0 \%)\end{array}$ & \multirow[t]{2}{*}{0,783} & $\begin{array}{c}0 \\
(0,0 \%)\end{array}$ & $\begin{array}{c}1 \\
(5,9 \%)\end{array}$ & $\begin{array}{c}0 \\
(0,0 \%)\end{array}$ & \multirow[t]{2}{*}{0,832} & $\begin{array}{c}0 \\
(0,0 \%)\end{array}$ & $\begin{array}{c}1 \\
(5,0 \%)\end{array}$ & \\
\hline $\begin{array}{l}\text { Ruim/ } \\
\text { Péssimo }\end{array}$ & $\begin{array}{c}17 \\
(94,4 \%)\end{array}$ & $5(100,0 \%)$ & & $\begin{array}{c}2 \\
(100,0 \%)\end{array}$ & $\begin{array}{c}16 \\
(94,1 \%)\end{array}$ & $\begin{array}{c}4 \\
(100,0 \%)\end{array}$ & & $\begin{array}{c}3 \\
(100,0 \%)\end{array}$ & $\begin{array}{c}19 \\
(95,0 \%)\end{array}$ & \\
\hline \multicolumn{11}{|c|}{$\begin{array}{l}\text { Frequência } \\
\text { mensal de raízes } \\
\text { e tubérculos }\end{array}$} \\
\hline $\begin{array}{l}\text { Ótimo/ } \\
\text { Bom }\end{array}$ & $\begin{array}{c}0 \\
(0,0 \%)\end{array}$ & $\begin{array}{c}0 \\
(0,0 \%)\end{array}$ & & $\begin{array}{c}0 \\
(0,0 \%)\end{array}$ & $\begin{array}{c}0 \\
(0,0 \%)\end{array}$ & $\begin{array}{c}0 \\
(0,0 \%)\end{array}$ & & $\begin{array}{c}0 \\
(0,0 \%)\end{array}$ & $\begin{array}{c}0 \\
(0,0 \%)\end{array}$ & \multirow{3}{*}{0,870} \\
\hline Regular & $\begin{array}{c}0 \\
(0,0 \%)\end{array}$ & $1(20,0 \%)$ & \multirow[t]{2}{*}{0,217} & $\begin{array}{c}0 \\
(0,0 \%)\end{array}$ & $\begin{array}{c}0 \\
(0,0 \%)\end{array}$ & $\begin{array}{c}1 \\
(25,0 \%)\end{array}$ & \multirow[t]{2}{*}{0,083} & $\begin{array}{c}0 \\
(0,0 \%)\end{array}$ & $\begin{array}{c}1 \\
(5,0 \%)\end{array}$ & \\
\hline $\begin{array}{l}\text { Ruim/ } \\
\text { Péssimo }\end{array}$ & $\begin{array}{c}18 \\
(100,0 \%)\end{array}$ & $4(80,0 \%)$ & & $\begin{array}{c}2 \\
(100,0 \%)\end{array}$ & $\begin{array}{c}17 \\
(100,0 \%)\end{array}$ & $\begin{array}{c}3 \\
(75,0 \%)\end{array}$ & & $\begin{array}{c}3 \\
(100,0 \%)\end{array}$ & $\begin{array}{c}19 \\
(95,0 \%)\end{array}$ & \\
\hline
\end{tabular}

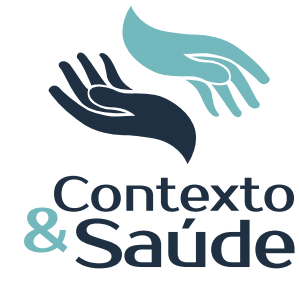

Observou-se associação significativa $(p<0,05)$ entre as variáveis perfil de organização espacial dos municípios e frequência de frutas $(p=0,019)$ (Tabela 3) e as variáveis perfil demográfico e perfil de organização espacial dos municípios $(p=0,001)$. Assim, todos os municípios rurais $(n=3)$ mostraram uma classificação ótima ou boa para a frequência mensal de frutas, enquanto os municípios urbanos tenderam a apresentar a maior parte dos resultados da frequência mensal deste marcador entre regular, ruim ou péssima.

Por outro lado, não houve associação significativa $(p>0,05)$ entre a compra da AF ou perfil demográfico do município e a frequência mensal dos marcadores da alimentação saudável, assim como entre o perfil de organização espacial do município e a frequência mensal de legumes, verduras, raízes e tubérculos (Tabela 3).

\section{DISCUSSÃO}

Os cardápios, no âmbito do PNAE, têm contribuído para ampliar o acesso dos escolares à alimentação e garantir o direito humano à alimentação adequada e saudável. Além disso, considera-se que a oferta de refeições balanceadas contribui com a formação de bons hábitos alimentares, sendo um importante instrumento de EAN no contexto escolar (SOARES et al., 2015).

A maioria dos cardápios analisados neste estudo apresentou frequência mensal inadequada de frutas, vegetais não amiláceos, vegetais folhosos e alimentos integrais, apesar de a presença dos mesmos nas refeições escolares ser considerada estratégica para a promoção de uma alimentação adequada e saudável.

Cabe destacar que a realidade das Unidades de Alimentação e Nutrição Escolares (Uane) públicas brasileiras pode ser bastante distinta entre os municípios quanto à estrutura física, disponibilidade de equipamentos e utensílios, qualificação e quantitativo dos manipuladores de alimentos. Sabe-se que tais fatores impactam diretamente na determinação dos alimentos integrantes dos cardápios escolares. As Uanes, de um modo geral, apresentam a estrutura físi- 
ca que mais se assemelha às cozinhas domésticas que, associada à quantidade insuficiente de mão de obra, pode dificultar a inclusão de vegetais folhosos nos cardápios e justificar os resultados encontrados neste trabalho, uma vez que estes alimentos demandam etapas específicas de pré-preparo e preparo (SOARES et al., 2015). Um estudo, ao avaliar cardápios escolares de um município do RJ (Brasil) pelo método AQPC, também encontrou baixa frequência de vegetais foIhosos (SOARES et al., 2015). Por outro lado, Boaventura et al. (2013), ao avaliarem cardápios escolares de três municípios de São Paulo, encontraram uma alta frequência de frutas e hortaliças.

Alguns estudos internacionais também demonstraram baixa presença de frutas e vegetais folhosos nos cardápios escolares de países como Espanha e Estados Unidos (URIARTE; LARREA; ALONSO, 2015; COPELAND et al., 2013).

A presença de alimentos integrais, além de contribuir para a formação de hábitos alimentares saudáveis nas crianças, também está relacionada à diminuição das chances do desenvolvimento de doenças crônicas não transmissíveis (DCNT) (VIDAL; VEIROS; SOUSA, 2015). Um fator limitante, entretanto, para a inclusão destes enquanto grupo de alimentos recomendados pelo método AQPCE nos cardápios escolares, pode ter relação com sua aceitabilidade. Em 2015, Alves, Marques e Bennemann verificaram que das quatro grandes refeições oferecidas a escolares de uma rede municipal de ensino no Paraná (Brasil) contendo arroz integral, três apresentaram índices de aceitabilidade abaixo de $85 \%$ pela escala hedônica facial.

A frequência adequada para cereais e leguminosas, em quase todos os cardápios deste estudo, decorreu da presença, quase que diária, de arroz ou macarrão e feijão preto, respectivamente. Sabe-se que ambos os alimentos são tradicionais e constituem a chamada dieta do brasileiro, justificando a presença dos mesmos no cardápio escolar (BRASIL, 2014).

Quanto aos alimentos controlados pelo método AQPCE, vale destacar que a maior parte destes é considerada, também, de uso restrito ou proibido de acordo com a legislação do PNAE (BRASIL, 2013a), e classificada como processado (alimentos enlatados e conservas) ou ultraprocessado (alimentos embutidos, produtos cárneos industrializados, molhos de tomate e bebidas de baixo valor nutricional, como refrigerantes) (BRASIL, 2014).

Para preparações alimentares e produtos com açúcar, as frequências mensais regulares, ruins ou péssimas nos cardápios foram em razão dos refrescos preparados à base de água, fruta e açúcar. Sabe-se que as bebidas açucaradas são consideradas preditoras de uma alimentação inadequada, e seu consumo na população parece estar relacionado ao baixo consumo de frutas, verduras e legumes, contribuindo, desta forma, para o aumento do risco de obesidade infantil (BRASIL, 2014; BRASIL, 2011).

Por outro lado, a ausência de refrigerantes, bebidas e concentrados à base de groselha e guaraná, além dos chás prontos para consumo, representados pelas bebidas de baixo valor nutricional nos cardápios escolares, pode ser considerada um resultado alinhado às estratégias da promoção da alimentação adequada e saudável (BRASIL, 2013b; BRASIL, 2006) e orientações do Guia Alimentar

Editora Unijuí - Revista Contexto \& Saúde - ISSN 2176-7114 - v. 21, n. 43, jul./set. 2021 
para a População Brasileira (BRASIL, 2014), levando em conta o aumento da prevalência de sobrepeso e obesidade em crianças brasileiras nas últimas décadas (BRASIL, 2010; SILVA et al., 2016).

Apenas um cardápio apresentou frequência mensal inadequada para enlatados e conservas, estando em desacordo com a legislação do PNAE, que determina aquisição restrita destes alimentos (BRASIL, 2013a). Boaventura et al. (2013) também destacaram a presença de alimentos restritos, tais como salsicha e linguiça, em até $18 \%$ dos cardápios escolares em São Paulo.

Diversos fatores podem interferir na seleção dos alimentos e preparações alimentares durante a etapa de planejamento de cardápios escolares pela equipe técnica de nutricionistas, e ajudam a explicar os resultados encontrados neste trabalho. Estes fatores podem variar desde a vocação agrícola de cada região, modelo de gestão do PNAE, características institucionais que facilitam ou dificultam a compra de gêneros da AF pelos municípios, entre outros, que podem afetar a maior ou menor disponibilidade de alimentos in natura, minimamente processados e processados na alimentação escolar. Sabe-se que diferentes modelos de gestão do PNAE - centralizado, descentralizado ou misto - e suas especificidades podem ser adotados pelos municípios, impactando diretamente na qualidade e na variedade de alimentos dos cardápios escolares. Nos sistemas descentralizado e semidescentralizado, por exemplo, a principal vantagem relaciona-se à maior possibilidade de compra de alimentos regionais, de produtos produzidos pela agricultura local e, consequentemente, de alimentos in natura, como frutas, legumes e verduras (SANTOS; COSTA; BANDEIRA, 2016).

Experiências prévias realizadas em municípios brasileiros indicam que, embora nas últimas décadas as políticas de Segurança Alimentar e Nutricional (SAN) tenham apoiado a construção de cadeias curtas de abastecimento, ainda existem dificuldades na efetivação dos $30 \%$ mínimos para a compra da AF na alimentação escolar. Nesse sentido, podemos destacar as dificuldades de organização e planejamento dos agricultores, problemas e custos de logística, falta de capacitação financeira e gerencial dos atores envolvidos ou de compreensão das possibilidades engendradas pela política pública, falta de documentação e interesse dos agricultores, desconfiança dos mesmos em relação ao poder público, inexistência de AF no local, inviabilidade de fornecimento regular e constante e falta de articulação entre gestores e agricultores fornecedores como determinantes para o não cumprimento da legislação (FERIGOLLO et al., 2017).

Nesse sentido, embora a compra de alimentos da AF tenha avançado, ao longo dos anos, com um crescimento médio nacional de 3,4\% ao ano (BRASIL, 2016a) em gêneros alimentícios oriundos da produção familiar, desafios institucionais no âmbito da gestão das compras públicas nos Estados e municípios brasileiros vêm afetando o potencial de inclusão desse seguimento de agricultores como fornecedores para o PNAE, podendo, dessa forma, refletir na qualidade dos cardápios escolares. Saraiva et al. (2013) destacam que, apesar da obrigatoriedade da compra da AF no PNAE, alguns municípios ainda encontram barreiras na aquisição destes alimentos em razão da presença de grandes empresas do setor envolvidas na compra pública de alimentos.

Editora Unijuí - Revista Contexto \& Saúde - ISSN 2176-7114 - v. 21, n. 43, jul./set. 2021 
No caso estudado, diversos cardápios apresentaram frequência inadequada para alimentos que podem ser supridos pela AF, tais como aqueles de origem vegetal. Nesse sentido, fatores que vão desde o processo de chamada pública, capacidade de atendimento à demanda do município até a falta de incentivos governamentais, podem dificultar a participação desse segmento na oferta de alimentos básicos para a alimentação escolar no RJ, e, consequentemente, comprometer a qualidade nutricional dos cardápios escolares (FERIGOLLO et al., 2017).

Baccarin et al. (2017), ao avaliarem a qualidade da alimentação escolar a partir da aquisição de alimentos da AF em dois municípios do Paraná em 2013, identificaram que o município que realizou maior aquisição de alimentos da AF também efetuou maiores investimentos em frutas e vegetais e maior variedade de alimentos nos cardápios. Os autores concluem que a aquisição de alimentos da AF permite o planejamento de um cardápio mais adequado, influenciando positivamente na qualidade do consumo alimentar dos escolares.

Os cardápios escolares desempenham um importante papel no estímulo da ingestão diária de frutas, legumes e verduras entre o público escolar, considerado um grupo vulnerável sob o ponto de vista socioeconômico no contexto brasileiro (SOARES et al.; 2015). Mesmo em âmbito internacional, quando as características dos programas de alimentação escolar diferem do modelo brasileiro, o acesso a refeições na escola favorece o maior consumo de vegetais comparado às crianças que trazem alimentos de casa (EVANS et al., 2015).

Nesse sentido, o cardápio da alimentação escolar deve ser encarado como um instrumento de planejamento que assegure a oferta de uma alimentação adequada e saudável e que atenda parte das necessidades nutricionais dos alunos durante o período letivo. $O$ uso de ferramentas para análise de cardápios escolares, tal como o método AQPCE, portanto, torna-se relevante para a avaliação da qualidade de cardápios e, por conseguinte, para a verificação do cumprimento das recomendações do PNAE. A utilização desta ferramenta brasileira, entretanto, pode dificultar a comparação com resultados de estudos nacionais e internacionais relacionados à qualidade de cardápios escolares com diferentes metodologias.

Quanto às limitações deste estudo, não foram analisados os cardápios de todos os municípios do RJ em razão de a maior parte deles não estar disponível nos sites eletrônicos das Prefeituras, mesmo devendo ser de domínio público. Outra limitação refere-se ao fato de que, nos cardápios planejados, não são disponibilizadas as matérias-primas necessárias à elaboração das preparações alimentares, dificultando a análise dos cardápios segundo algumas variáveis do método AQPCE.

No caso da variável frituras, carnes e molhos gordurosos, a frequência inadequada encontrada em três cardápios dos almoços foi pela presença das preparações "estrogonofes de carne e frango", tipicamente elaboradas com cremes de leite, tendo em vista que a análise do tipo de carne, quanto ao teor de gordura, tornou-se inviável a partir do acesso aos cardápios pela falta de informações sobre as matérias-primas alimentares.

Editora Unijuí - Revista Contexto \& Saúde - ISSN 2176-7114 - v. 21, n. 43, jul./set. 2021 
A efetividade do PNAE e o alcance dos seus objetivos decorre do desenvolvimento e do fortalecimento de uma rede de contato e diálogo entre o agricultor familiar local e o gestor da alimentação escolar no município para o planejamento de cardápios e compras de alimentos que reflita no desenvolvimento econômico social local, oferta de uma alimentação escolar em consonância com as diretrizes do PNAE e manutenção destes mercados institucionais.

\section{CONCLUSÃO}

Este estudo propôs-se a analisar a qualidade de cardápios dos almoços planejados para escolares de municípios do RJ e verificar a associação entre a presença de alimentos de origem vegetal nestes cardápios com a compra da AF, o perfil demográfico e de organização espacial de municípios do RJ. Os resultados demonstraram que a maioria dos cardápios apresentou frequência mensal inadequada de alguns alimentos de origem vegetal, especialmente frutas e vegetais folhosos. Verificou-se, também, que a maioria dos municípios não atingiu o percentual mínimo exigido dentro do contexto do PNAE para a compra de alimentos pela AF. Mais ainda, o atendimento deste parâmetro em alguns municípios não contribuiu para o aumento significativo da frequência mensal de alimentos marcadores da alimentação saudável nos cardápios analisados.

Assim, a criação de estratégias para uma maior e constante aquisição de alimentos de origem vegetal oriundos da AF para a alimentação escolar, nos municípios cujos cardápios foram objetos de estudo neste trabalho, é considerada um passo importante não somente pelo aumento da possibilidade de oferecer alimentos saudáveis, mas também por contribuir para o cumprimento das legislações do PNAE quanto à oferta de uma alimentação adequada, sustentável e promotora do desenvolvimento econômico local.

\section{REFERÊNCIAS}

ALVES, E.; MARQUES, A. G.; BENNEMANN, R. M. Avaliação da composição nutricional e da aceitabilidade da merenda oferecida na rede municipal de ensino da cidade de Maringá - PR. Enciclopédia Biosfera, v. 11, n. 22, p. 3.195-3.206, 2015.

BACCARIN, J. G.; TRICHES, R. M.; TEO, C. R. P. A.; SILVA, D. B. P. Indicadores de avaliação das compras da agricultura familiar para alimentação escolar no Paraná, Santa Catarina e São Paulo. Revista de Economia e Sociologia Rural, v. 55, n. 1, p. 103-122, 2017.

BOAVENTURA, P. S.; OlIVEIRA, A. C.; COSTA, J. J.; MOREIRA, P. V. P.; MATIAS, A. C. G.; SPINELLI, M. G. N.; ABREU, E. S. Avaliação qualitativa de cardápios oferecidos em escolas de educação infantil da grande São Paulo. Demetra: Alimentação, Nutrição \& Saúde, v. 8, n. 3, p. 397-409, 2013.

BOITO, T.; HARTMANN, V.; KÜMPEL, D. A; CARLI, G. Avaliação de cardápios de uma escola de educação infantil. Revista Contexto \& Saúde, v. 19, n. 36, p. 14-19, jan./jun. 2019.

BRASIL. Ministério da Saúde. Portaria Interministerial no 1.010, de 08 de maio de 2006. Institui as diretrizes para a Promoção da Alimentação Saudável nas Escolas de educação infantil, fundamental e nível médio das redes públicas e privadas, em âmbito nacional. 2006. Disponível em: http://bvsms.saude.gov.br/bvs/saudelegis/gm/2006/ pri1010_08_05_2006.html. Acesso em: 20 dez. 2018.

BRASIL. Lei no 11.947, de 16 de junho de 2009. Dispõe sobre o atendimento da alimentação escolar e do Programa Dinheiro Direto na Escola aos alunos da educação básica.

Editora Unijuí - Revista Contexto \& Saúde - ISSN 2176-7114 - v. 21, n. 43, jul./set. 2021 
2009a. Disponível em: http://www.planalto.gov.br/ccivil_03/_ato2007-2010/2009/lei/ 111947.htm. Acesso em: 18 mar. 2018.

BRASIL. Ministério da Educação; Fundo Nacional de Desenvolvimento da Educação; Conselho Deliberativo. Resolução no 38 de 16 de julho de 2009. Dispõe sobre o atendimento da alimentação escolar aos alunos da educação básica no Programa Nacional de Alimentação Escolar - PNAE. 2009b. Disponível em: https://www.fnde.gov.br/acesso-a-informacao/institucional/legislacao/item/3341-resolução-cd-fnde-no-38-de-16-de-juIho-de-2009. Acesso em: 10 nov. 2018.

BRASIL. Ministério do Planejamento, Orçamento e Gestão. Instituto Brasileiro de Geografia e Estatística - IBGE. Diretoria de Pesquisas. Coordenação de Trabalho e Rendimento. Pesquisa de Orçamentos Familiares 2008-2009. Antropometria e Estado Nutricional de Crianças, Adolescentes e Adultos no Brasil. 2010. Disponível em: https://biblioteca.ibge. gov.br/visualizacao/livros/liv45419.pdf. Acesso em: 12 dez. 2018.

BRASIL. Ministério do Planejamento, Orçamento e Gestão. Instituto Brasileiro de Geografia e Estatística - IBGE. Diretoria de Pesquisas. Coordenação de Trabalho e Rendimento. Pesquisa de Orçamentos Familiares 2008-2009: análise do consumo alimentar pessoal no Brasil. 2011. Disponível em: https://biblioteca.ibge.gov.br/visualizacao/livros/ liv50063.pdf. Acesso em: 10 dez. 2018.

BRASIL. Ministério da Educação. Fundo Nacional de Desenvolvimento da Educação. Resolução/CD/FNDE $n^{\circ} 26$, de 17 de junho de 2013. Dispõe sobre o atendimento da alimentação escolar aos alunos da educação básica no âmbito do Programa Nacional de Alimentação Escolar - PNAE. 2013a. Disponível em: https://www.fnde.gov.br/acesso-a-informacao/institucional/legislacao/item/4620-resolução-cd-fnde-no-26,-de-17-de-junho-de-2013. Acesso em: 5 nov. 2018.

BRASIL. Ministério da Saúde. Secretaria de Atenção à Saúde. Departamento de Atenção Básica. Política Nacional de Alimentação e Nutrição. 2013b. Disponível em: http://bvs$\mathrm{ms}$.saude.gov.br/bvs/publicacoes/politica_nacional_alimentacao_nutricao.pdf. Acesso em: 1ㅇdez. 2018.

BRASIL. Ministério da Saúde. Secretaria de Atenção à Saúde. Departamento de Atenção Básica. Guia alimentar para a população brasileira. 2014. Disponível em: http://bvsms. saude.gov.br/bvs/publicacoes/guia_alimentar_populacao_brasileira_2ed.pdf. Acesso em: 15 set. 2018.

BRASIL. Fundo Nacional de Desenvolvimento da Educação. Nota Técnica no 5003/2016/ DIDAF/COSAN/CGPAE/DIRAE. 2016a. Disponível em: http://www.fnde.gov.br/component/k2/item/5194-notas-técnicas-pareceres-relatórios. Acesso em: 6 nov. 2018.

BRASIL. Ministério da Educação. Fundo Nacional de Desenvolvimento da Educação. Diretoria de Ações Educacionais - DIRAE. Coordenação Geral do Programa de Alimentação Escolar - CGPAE. Dispõe sobre valores investidos na aquisição de gêneros alimentícios diretamente da agricultura familiar para o PNAE, ano exercício 2016. 2016b. Disponível em: http://www.fnde.gov.br/programas/pnae/pnae-consultas/pnae-dados-da-agricultura-familiar. Acesso em: 19 jan. 2018.

BRASIL. Ministério do Planejamento, Desenvolvimento e Gestão. Classificação e caracterização dos espaços rurais e urbanos do Brasil: uma primeira aproximação. 2017. Disponível em: https://biblioteca.ibge.gov.br/visualizacao/livros/liv100643.pdf. Acesso em: 19 nov. 2018.

COPELAND, K. A.; NEELON, S. E. B.; HOWALD, A. E.; WOSJE, K. S. Nutritional quality of meals compared to snacks in child care. Childhood Obesity, v. 9, n. 3, p. 223-232, jun. 2013.

CRUZ, L. Z.; SANTOS, A. J. A. O.; SANTOS, A. A. O.; GOMES, A. B. L.; ANDRADE, F. A. M.; MARCELLINI, P. S. Análise de aceitação da alimentação escolar dos alunos das escolas municipais urbanas de Itabaiana-SE. Scientia Plena, v. 9, n. 10, p. 1-6, 2013.

EVANS, A. E. L.; MANDL, V.; CHRISTIAN, M. S.; CADE, J. E. Impact of school lunch type on nutritional quality of English children's diets. Public Health Nutrition, v. 19, n. 1, p. 36-45, 2015.

Editora Unijuí - Revista Contexto \& Saúde - ISSN 2176-7114 - v. 21, n. 43, jul./set. 2021 
FERIGOLLO, D.; KIRSTEN, V. R.; HECKLER, D.; FIGUEREDO, O.; PEREZ-CASSARINO, J.; TRICHES, R. M. Aquisição de produtos da agricultura familiar para alimentação escolar em municípios do Rio Grande do Sul. Revista de Saúde Pública, v. 51, n. 6, p. 1-10, 2017.

OMS. Organização Mundial de Saúde. 2003. Fruit and vegetable promotion initiative-report of the meeting. Disponível em: https://apps.who.int/iris/bitstream/handle/10665/68395/WHO_NMH_NPH_NNP_0308.pdf?sequence=1\&isAllowed=y. Acesso em: 10 out. 2018.

PRADO, B. G.; NICOLETTI, A. L.; FARIA, C. S. Avaliação qualitativa das preparações de cardápio em uma unidade de alimentação e nutrição de Cuiabá-MT. Unopar Científica Ciências Biológicas e da Saúde, v. 15, n. 3, p. 219-223, 2013.

SANTOS, S. R.; COSTA, M. B. S.; BANDEIRA, G.T. P. As formas de gestão do Programa Nacional de Alimentação Escolar (PNAE). Revista de Salud Publica, v. 18, n. 2, p. 311-320, 2016.

SARAIVA, E. B.; SILVA, A. P. F.; SOUSA, A. A.; CERQUEIRA, G. F.; CHAGAS, C. M. S.; TORA, N. Panorama da compra de alimentos da agricultura familiar para o Programa Nacional de Alimentação Escolar. Ciência e Saúde Coletiva, v. 18, n. 4, p. 927-936, 2013.

SILVA, X. S.; MARTINS, M. L.; PIERUCCI, A. P. T. R.; PEDROSA, C.; ROCHA, A. Análise qualitativa de ementas em escolas do Rio de Janeiro. Acta Portuguesa de Nutrição, v. 6, p. 6-12, set. 2016.

SOARES, D. S. B.; BARBOSA, R. M. S.; HENRIQUES, P.; DIAS, P. C.; FERREIRA, D. M. Quality analysis of menus of the National School Feeding Program in a city of Rio de Janeiro State - Brazil. Revista Chilena de Nutrición, v. 42, n. 3, p. 235-240, set. 2015.

TEO, C. R. P. A.; MONTEIRO, C. A. Marco legal do Programa Nacional de Alimentação Escolar: uma releitura para alinhar propósitos e práticas na aquisição de alimentos. Revista de Nutrição, v. 25, n. 5, p. 657-668, set./out. 2012.

URIARTE, P. S.; LARREA, F. B. C.; ALONSO, S. V. Características nutricionales de los menús escolares en Bizkaia (País Vasco, España) durante el curso 2012/2013. Nutrición Hospitalaria, v. 31, n. 3, p. 1.309-1.316, 2015.

VEIROS, M. B.; MARTINELLI, S. S. Avaliação qualitativa das preparações do cardápio Escolar - AQPC escola. Nutrição em Pauta, v. 20, n. 114, p. 3-12, maio/jun. 2012.

VIDAL, G. M.; VEIROS, M. B.; SOUSA, A. A. School menus in Santa Catarina: evaluation with respect to the National School Food Program regulations. Revista de Nutrição, v. 28, n. 3, p. 277-287, maio/jun. 2015. 